The typical symptoms of advanced cancer of the stomach are well known in clinical practice. The presented case concerns a patient with symptoms of left-sided renal colic, caused by a malignant tumour involving the ureter, which was diagnosed with a CT scan. The multifocal process, involving the stomach, two parts of the colon, the left ovary and the side of the pelvis, was confirmed only during surgery.

The resection or partial resection of the above-mentioned organs involved by the malignant process and reconstruction of the alimentary tract as well as the ureter were performed at time of this operation. The patient's recovery was without any complications. The histopathological findings support the diagnosis of this malignant process as disseminated stomach cancer.

In the available literature only two cases of stomach cancer metastasis to the ureter have been described. In both cited examples resection of the ureter with nephrectomy was performed. The review of the literature supports the value of stomach palliative resection in prolonging life and improving quality of life.

Key words: advanced stomach cancer, palliative stomach resection, renal colic.

\section{Left-sided renal colic as a symptom of advanced stomach cancer - a case report}

\author{
Janusz Godlewski ${ }^{12}$, Grażyna Kuciel-Lisieska', Grażyna Licznerska', \\ Michat Tenderenda ${ }^{1}$
}
1Division of Oncology, Department of Oncological Surgery, Faculty of Medical Sciences, University of Warmia and Mazury in Olsztyn, Poland
2Department of Human Histology and Embryology; Faculty of Medical Sciences, University of Warmia and Mazury in Olsztyn, Poland

\section{Introduction}

Gastric cancer is the second most frequent neoplasm of the alimentary tract after the large intestine. 5,103 people in Poland were affected by it in 2008. The case-to-death ratio of around 1 indicates unfavourable prognosis as to recovery from this disease $[1,2]$. This poor result is determined by the fact that it is rarely (only in around $8 \%$ ) detected in the form of early gastric cancer, in the mildly symptomatic or asymptomatic phase. In most patients it is diagnosed at a higher degree than the 1st degree of disease progression and its classic symptoms are weight loss, continuous and dull pain in the epigastrium, loss of appetite, nausea, vomiting and chronic bleeding [3, 4]. This paper presents rare symptoms of disseminated gastric cancer manifested as renal colic. The existence of gastric cancer metastasis to the ureter has been described twice in the literature to date.

\section{Case report}

A female patient, age 67, was diagnosed at the district hospital (22.0430.04.2010) because of intensified symptoms of left-sided renal colic. Based on the conducted USG and single-phase computed tomography tests of the abdominal cavity and the pelvis, dilation of the ureter was found because of its infiltration by a pathological focus with the dimensions of $28 \mathrm{~mm} \times 15 \mathrm{~mm}$. Another lesion was located nearby at the level of the left iliac muscle $-30 \mathrm{~mm} \times 27 \mathrm{~mm} \times 20 \mathrm{~mm}$, adhering to the sigmoid colon. Tissue infiltration of the pelvis minor wall was found descending in the direction of the left appendages. Colonoscopy was conducted and in this test the large intestine was described without pathology, while the gynaecological USG test confirmed the presence of fluid in the pelvis. During her stay the patient was treated with analgesic and diastolic medication and then referred for further treatment at the regional oncology centre.

Because of reported pain complaints, she was immediately admitted to the department of oncological surgery on the day of her visit to the outpatient clinic (04.05.2010). The urologist consulting the patient indicated the possibility of kidney damage due to ureteral obstruction with recommendation for an accelerated operation. Therefore, pre-operative diagnostics were not extended beyond the tests received from the district hospital. The patient underwent surgery on 10.05.2010 and intraoperatively, besides the expected neoplastic tumour of the left ovary with infiltration of the ureter, numerous neoplastic foci were also found: a sigmoid colon tumour, a caecum tumour, a tumour of the body of the stomach and two single tumours in the omentum. Because of the resectability of the neoplastic foci described above, the operation plan adopted earlier was changed and the following were performed in succession with palliative intention: partial gastrectomy by the Rydygier method, right-sided hemicolectomy, left ovariectomy and sigmoid resection. After restoring the continuity of the alimentary 


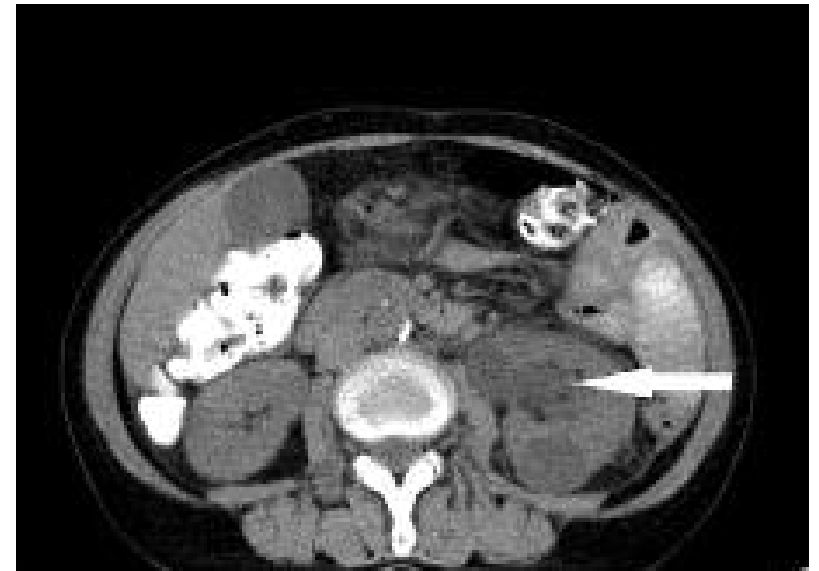

Fig. 1. CT axial scan. The widening of the left ureter is visible (marked by arrow)
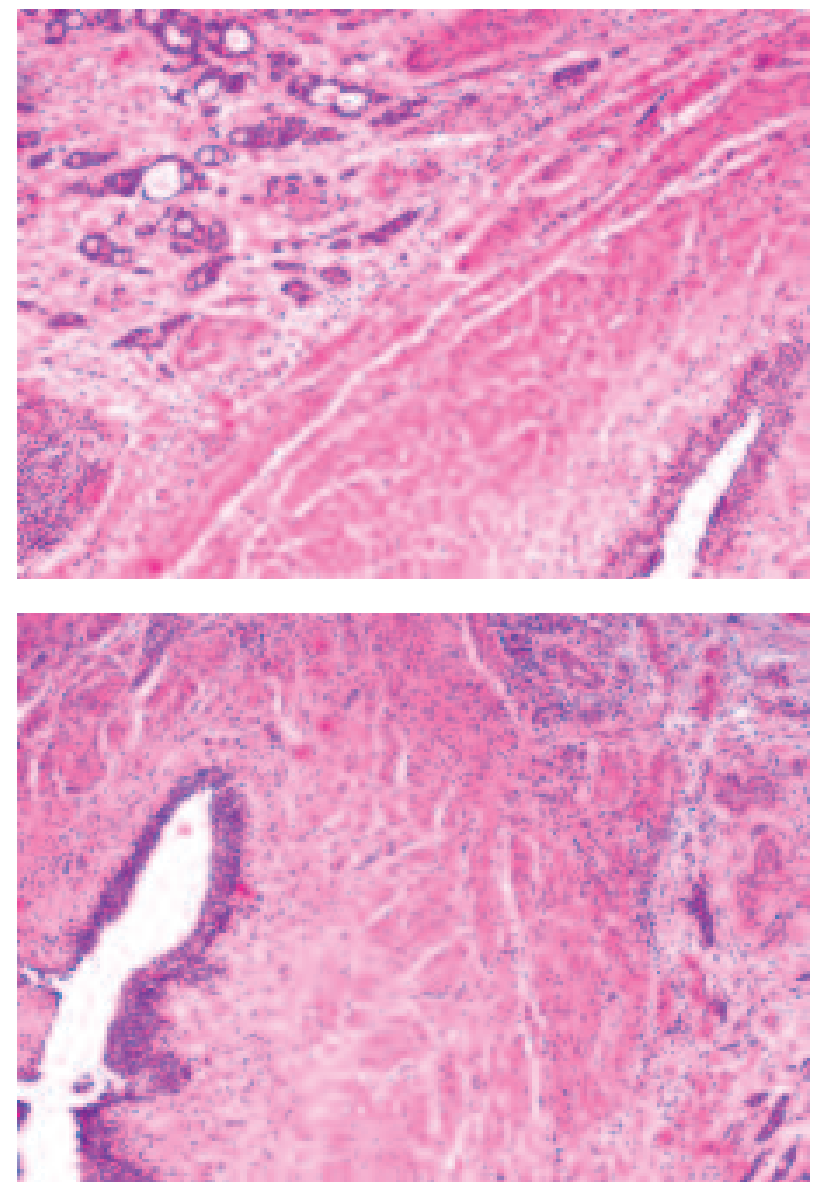

Fig. 2 and 3. Focus of metastatic carcinoma in the ureter wall. Microscopic section, HE staining, magnification $40 \times$

tract, the technically difficult resection of the neoplastic tumour in the left ureter was started. The tumour occluded the lumen, which is why segmental ureterectomy was performed with endto-end anastomosis over a pigtail catheter. The operative procedure lasted a total of $3 \mathrm{hrs} 20 \mathrm{~min}$. The patient passed the post-operative period without complications, except a two-day fever. Because of the expected alimentary tract failure, parenteral nutrition was included on the 1st day after the procedure and blood deficits were supplemented with 2 units of ery-

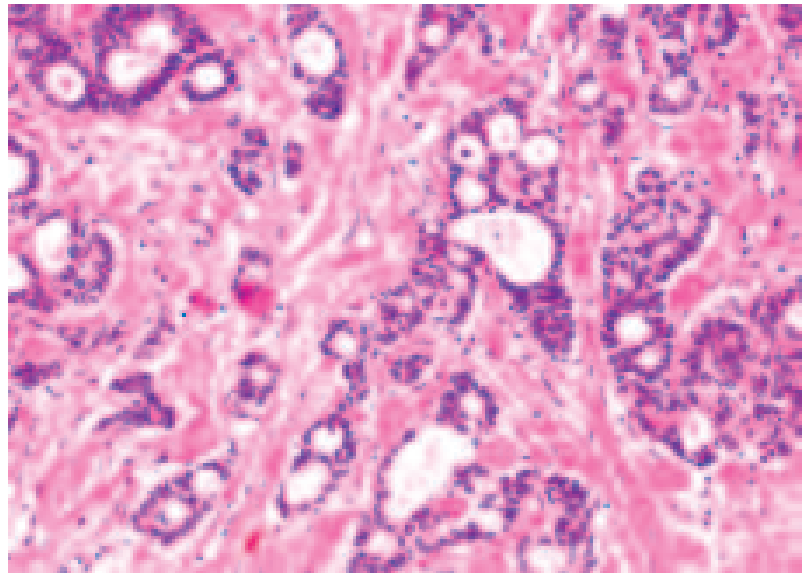

Fig. 4. Neoplastic invasion in the ureter wall. Microscopic section, HE staining, magnification $100 \times$

throcyte mass and 7 units of plasma. On the 9th day after the operation, the patient was discharged home in a good general condition with recommendations for further treatment. The received postoperative histopathological protocol indicated that the stomach was the origin of the neoplastic process. It was the intestinal form (acc. to Lauren), type I (acc. to Goseki), of a stomach adenocarcinoma with a G2 malignancy degree, with occupation of the whole thickness of the stomach wall, with the following immunohistochemical characteristics: CK7(+++), CK20(++), CA125(+), Mucicarmine(+). Neoplastic infiltrations along nerves and neoplastic embolisms of blood vessels, as well as metastatic foci in the greater omentum, were observed in the specimen. Because of the palliative partial gastrectomy type, only 3 lymph nodes were described in this specimen and all of them contained neoplastic cells. Besides the above, histopathological confirmations were obtained of the metastatic character of the foci in the ovary, caecum and sigmoid colon. The cancer occupied large and small intestine walls without infiltration of the mucous membrane and the immunohistochemical characteristics were identical as for the primary lesion. According to the above protocol, excision within tissues with a healthy margin of these organs was achieved.

It is interesting biologically and constitutes the basis for this paper that the ureteral tumour was described by the pathologists not as a neoplastic infiltration encroaching on the ureter, but as a metastatic focus to the ureteral wall.

After the operative treatment, the patient was qualified for palliative chemotherapy and received it from 28.07.2010. The first treatment course was according to the EOX regimen (oxaliplatin and capecitabine), but because of the occurrence of neutropenic fever the regimen was changed to PF (cisplatin and 5-fluorouracil). She again received only one course and the treatment was changed once more because newly formed metastatic foci in the liver were located in imaging tests. Next, three chemotherapy courses were administered according to the FOLFIRI regimen (irinotecan, leucovorin and 5-fluorouracil), but only until 11.11 .2010 because due to progression of changes in the liver described in examinations the chemotherapy was discontinued and the patient was qualified for symptomatic treatment. According to our knowledge, the patient died in January 2011. 


\section{Discussion}

Treatment of gastric cancer in the disseminated phase of the disease aims at extension of life and achieving a good palliative effect. The recommended methods, allowing the above to be achieved, are chemotherapy or combination radiochemotherapy. In an advanced stage, palliative operations on this organ are performed for life reasons and serve to eliminate complications such as bleeding, perforation or obstruction of the organ. It is indicated that the above complications forced surgical intervention in $1 / 4$ of the patients previously disqualified from operative treatment because of the presence of metastatic foci. According to literature data, patients operated on by palliative resection in the disseminated phase of the disease achieve a survival time of between 9 and 15 months. The survival time is limited by the number of metastatic foci; when their number is higher than two foci, no statistically significant differences are observed in this scope. The value of these procedures is increasing because of the reported low perioperative mortality and the observed significant improvement in the further quality of life for these patients [5-13]. It seems that the operative procedure conducted in the presented patient allowed a good palliative effect to be achieved along with loss of severe colic and maintenance of kidney function. The literature often presents, as characteristic of gastric cancer, bloodborne metastasis to the ovary, termed a Krukenberg tumour. Metastasis of a similar type occurred in this patient. This is a term generally defining metastasis to the ovary, mainly gastric cancer and next colon cancer. Metastases from other organs, such as the lungs, the mammary gland and the uterus, are also possible, though much rarer. Krukenberg tumours are encountered in the course of $2-4 \%$ of disseminated neoplastic processes. This is a negative prognostic factor, with varying median survival time after its diagnosis: 12-13 months in the course of gastric cancer compared to 17-29 months in the course of large intestine cancer. This undoubtedly results from biological differences in the course of these neoplasms [14-23].

In summary, the rare character of gastric cancer metastasis to the ureter should be stressed.

The available literature sources have described this only twice to date (in 1976 and 2000). However, nephroureterectomy was conducted in these quoted cases [24, 25]. In the presented patient the kidney was spared and healing of the ureter after endto-end suture was achieved. No uroplania or renal failure were observed in the postoperative period. It seems that such a surgical management strategy is worth presenting.

The dissemination of a neoplasm with extremely rarely encountered symptomatology described above is an interesting experience which we wanted to share. The beginning of the symptomatic disease as a left-sided renal colic is, in itself, a previously unreported case.

\section{References}

1. Zakład Epidemiologii i Prewencji Nowotworów, Centrum Onkologii - Instytut, Krajowa baza danych nowotworowych (2008) http://www.onkologia.org.pl/pl/p/7/.

2. Wojciechowska U, Didkowska J, Zatoński W. Nowotwory złośliwe w Polsce w 2006 roku. Biuletyn Centrum Onkologii 2006; 86.

3. Zarys chirurgii onkologicznej. Kopacz A (ed.). Akademia Medyczna w Gdańsku 2000; 171.

4. Nowotwory przewodu pokarmowego. Krawczyk M (ed.). Wydawnictwo Lekarskie PZWL, Warszawa 2001; 153-5.
5. Hartgrink HH, Putter H, Klein KE, Bonenkamp JJ, van de Velde CJ. Value of palliative resection in gastric cancer. Br J Surg 2002; 89: 1438-43. 6. Kunisaki C, Shimada H, Akiyama H, Nomura M, Matsuda G, Ono H. Survival benefit of palliative gastrectomy in advanced incurable gastric cancer. Anticancer Res 2003; 23: 1853-8.

7. Moriwaki Y, Kunisaki C, Kobayashi S, Harada H, Imai S, Kasaoka C. Does the surgical stress associated with palliative resection for patients with incurable gastric cancer with distant metastasis shorten their survival? Hepatogastroenterology 2004; 51: 872-5.

8. Zhang XF, Huang CM, Lu HS, Wu XY, Wang C, Guang GX, Zhang JZ, Zheng $\mathrm{CH}$. Surgical treatment and prognosis of gastric cancer in 2,613 patients. World J Gastroenterol 2004; 10: 3405-8.

9. Kahlke V, Bestmann B, Schmid A, Doniec JM, Kuchler T, Kremer B. Palliation of metastatic gastric cancer: impact of preoperative symptoms and the type of operation on survival and quality of life. World J Surg 2004; 28: 369-75.

10. Samarasam I, Chandran BS, Sitaram V, Perakath B, Nair A, Mathew G. Palliative gastrectomy in advanced gastric cancer: is it worthwhile? ANZ J Surg 2006; 76: 60-3.

11. Kunisaki C, Makino H, Takagawa R, et al. Impact of palliative gastrectomy in patients with incurable advanced gastric cancer. Anticancer Res 2008; 28: 1309-15.

12. Lin SZ, Tong HF, You T, et al. Palliative gastrectomy and chemotherapy for stage IV gastric cancer. J Cancer Res Clin Oncol 2008; 134: 187-92.

13. Sarela Al, Yelluri S. Gastric adenocarcinoma with distant metastasis: is gastrectomy necessary? Arch Surg 2007; 142: 143-9.

14. Yada-Hashimoto N, Yamamoto T, Kamiura S, Seino H, Ohira H, Sawai K, Kimura T, Saji F. Metastatic ovarian tumors: a review of 64 cases. Gynecol Oncol 2003; 89: 314-7.

15. Cheong JH, Hyung WJ, Chen J, Kim J, Choi SH, Noh SH.Surgical management and outcome of metachronous Krukenberg tumors from gastric cancer. J Surg Oncol 2004; 87: 39-45.

16. Cheong JH, Hyung WJ, Chen J, Kim J, Choi SH, Noh SH. Survival benefit of metastasectomy for Krukenberg tumors from gastric cancer. Gynecol Oncol 2004; 94: 477-82.

17. Gottwald L, Jakubik J, Goral E, Korczynski J, Kordek R, Bienkiewicz A. [Krukenberg tumor - common problem of gynecologists, surgeons oncologists and pathologists. Report of three cases and review of the literature]. Ginekol Pol 2006; 77: 58-62.

18. Kiyokawa T, Young RH, Scully RE. Krukenberg tumors of the ovary: a clinicopathologic analysis of 120 cases with emphasis on their variable pathologic manifestations. Am J Surg Pathol 2006; 30: 277-99.

19. Young RH. From krukenberg to today: the ever present problems posed by metastatic tumors in the ovary: part I. Historical perspective, general principles, mucinous tumors including the krukenberg tumor. Adv Anat Pathol 2006; 13: 205-27.

20. Young RH. From Krukenberg to today: the ever present problems posed by metastatic tumors in the ovary. Part II. Adv Anat Pathol 2007; 14: 149-77.

21. Yook JH, Oh ST, Kim BS. Clinical prognostic factors for ovarian metastasis in women with gastric cancer. Hepatogastroenterology 2007; 54: 955-9.

22. Jiang R, Tang J, Cheng X, Zang RY. Surgical treatment for patients with different origins of Krukenberg tumors: outcomes and prognostic factors. Eur J Surg Oncol 2009; 35: 92-7.

23. Kim WY, Kim TJ, Kim SE, Lee JW, Lee JH, Kim BG, Bae DS. The role of cytoreductive surgery for non-genital tract metastatic tumors to the ovaries. Eur J Obstet Gynecol Reprod Biol 2010; 149: 97-101.

24. Fitch WP, Robinson JR, Radwin HW. Metastatic carcinoma of the ureter. Arch Surg 1976; 111: 874-6.

25. Shimoyama Y, Ohashi M, Hashiguchi N, et al. Gastric cancer recognized by metastasis to the ureter. Gastric Cancer 2000; 3: 102-5.

\section{Address for correspondence}

Janusz Godlewski MD, PhD

Bankowców 35

10-628 Olsztyn, Poland

tel. +48698694528

e-mail: janusz350@poczta.onet.pl

Submitted: $\quad$ 15.08.2011

Accepted: $\quad 8.12 .2011$ 